\title{
Tumor lysis syndrome after chemotherapy for metastatic colic carcinoma: About two
} adult cases

\author{
Abaza $\mathrm{H}^{1 *}$, Sallami $\mathrm{S}^{2}$, Ben Chaabene $\mathrm{A}^{1}$ and Gara $\mathbf{S}^{1}$ \\ ${ }^{1}$ Clinical Biology Department, Institute Salah Azaïz, Tunis, Tunisia \\ ${ }^{2}$ Surgery Department, Nabeul Hospital, Nabeul, Tunisia
}

Received: 02 April, 2020

Accepted: 18 April, 2020

Published: 20 April, 2020

*Corresponding author: Abaza H, Clinical Biology Department, Institute Salah Azaïz, Tunis, Tunisia, E-mail: abazahajera@yahoo.fr

Keywords: Cancer; Lysis syndrome; Chemotherapy; Colon; Hyperuricemia

https://www.peertechz.com

Check for updates

\section{Abstract}

Tumor Lysis Syndrome (TLS) is a major oncological emergency involving metabolic perturbations. It occurs when tumor cells release their contents into the bloodstream, either spontaneously or in response to therapy. TLS is characterized by hyperuricemia, hyperkalemia, hyperphosphatemia and hypocalcemia following massive lysis of malignant cells. Although this syndrome is well described, it is rarely seen or suspected in solid malignancies. The frequency and severity of TLS is partly dependent upon the biology of the disease and type of therapy administered. We report in this work two cases of tumor lysis syndrome occurring after chemotherapy for endocrine colon carcinoma with small metastatic cells.

\section{Introduction}

Tumor lysis syndrome is an oncological emergency with potentially serious consequence $[1,2]$. It results from massive tumor cell lysis, sometimes spontaneous but most often secondary to local or systemic treatment of cancerous lesions $[2,3]$.

This syndrome is more frequently described in the case of malignant hemopathies (high grade lymphomas, acute leukemias) [1,2]. Solid tumors are rarely complicated by tumor lysis syndrome $[1,2,3]$.

It most often combines hyperuricemia, hyperkalemia, hyperphosphatemia, hypocalcaemia and an increase in serum Lactate Deshydrogenase (LDH) [2,3].

\section{Observation 1}

A 46-year old female who was in a normal state of health until five months prior to this admission was diagnosed as having colonic cancer following initial work-up for upper right abdominal pain. She had no family history of cancer. She underwent left colectomy
The three-layer immunoperoxidase histological analysis on dewaxed sections confirmed an endocrine tumor with poorly differentiated small cells with positive cytoplasmic labeling for antichromogranin and for antisynaptophysin.

An abdominal CT scan found diffuse liver metastases invading approximately $70 \%$ of the hepatic parenchyma. Before chemotherapy, Serum Glutamo Pyruvate Transférase (SGPT) was 4N, Glutamo Oxalo acétate Transférase (SGOT) was $4 \mathrm{~N}$ and alkaline phosphatase was $5 \mathrm{~N}$. She underwent chemotherapy: cisplatin (100mg/ $\mathrm{m}^{2}$ fist day) and etoposide (120mg/m² day 1 to day 3) combined with hydration with three liters of $2.5 \%$ glucose solution, $500 \mathrm{ml}$ of $10 \%$ mannitol and 20mg of furosemide. Multidisciplinary Concertation Meeting decided adjuvant chemotherapy. (FOLFIRI+cetuximab (Cmab) therapy).

After the first chemotherapy session (and despite hyperhydratation), the patient presented significant localized pain in the right hypochondrium, tachypnea and tachycardia but without digestive intolerance. Biological tests revealed showed severe acidosis acute renal failure, hyperuricemia, hyperphosphatemia, elevation of Lactic Deshydrogenase (LDH) (Table1). 
Table1: Metabolic disturbances occurring after the administration of the chemotherapy.

\begin{tabular}{|c|c|c|c|c|c|}
\hline Normal Values & $\begin{array}{c}\mathbf{1 3 5 - 2 1 4} \\
\text { UI/I }\end{array}$ & $\begin{array}{c}\mathbf{1 4 2 - 3 3 9} \\
\boldsymbol{\mu m o l} / \mathbf{I}\end{array}$ & $\begin{array}{c}\mathbf{3 . 5 - 4 . 5} \\
\mathbf{m m o l} / \mathbf{I}\end{array}$ & $\begin{array}{c}\mathbf{2 . 1 5 - 2 . 5 5} \\
\mathbf{m m o l} / \mathbf{l}\end{array}$ & $\begin{array}{c}\mathbf{0 . 8 1 - 1 . 4 5} \\
\mathbf{m m o l} / \mathbf{l}\end{array}$ \\
\hline $\begin{array}{c}\text { Before } \\
\text { chemotherapy }\end{array}$ & 541 & 307 & 4.7 & 2.5 & 1.12 \\
\hline $\begin{array}{c}\text { 3 days after } \\
\text { chemotherapy }\end{array}$ & 972 & 475 & 4.7 & 2.2 & 1.73 \\
\hline $\begin{array}{c}\text { 1 mouth after } \\
\text { chemotherapy }\end{array}$ & 365 & 600 & 4.8 & 2.33 & 0.84 \\
\hline
\end{tabular}

Clinical findings and biological disturbances had confirmed the diagnosis of tumor lysis syndrome.

The patient was treated by hyperhydration and urine alkalization (3 liters of physiological saline and 1 liter of bicarbonate at $14 \%$ per 24 hours), with normalization of metabolic anomalies.

The third curse of chemotherapy had modified in favor of combination of carboplatin and etoposide taking into account the occurene of severe hearing loss secondary to cicplatin. Alkaline hyperhydration (3 littres of physiological saline and 1 liter baking soda at $14 \%$ per 24 hours) started the day before and continued during the cure could prevent a recurrence of the tumor lysis syndrome. An abdominal scanner performed after this last course had confirmed a regression of about $50 \%$ of liver damage and a quasi-normalization hepatic assessment (ASAT: N, ALAT: N, PAL: 1.9N).

\section{Observation 2}

A 52-year-old women, with no significant medical history, was diagnosed with a well differentiated adenocarcinoma of the left colic angle, metastasized to the liver and spleen. Multidisciplinary Concertation Meeting decided surgical ablation of the tumor and chemotherapy for metastasis She underwent a left colectomy followed by 3 monthly FOLFOXbased chemotherapy courses. One week after the third session, biological tests showed a serum elevation of uric acid to 500 $\mu \mathrm{mol} / \mathrm{l}$ and of LDH to $600 \mathrm{IU} / \mathrm{l}$. Despite alkaline hyperhydration, the evolution was marked by the progressive deterioration of the general state.

\section{Discussion}

Tumor lysis syndrome results from the massive destruction of neoplastic cells, most often following a chemotherapy or radiation therapy $[1,4,5]$. More rarely, it can occur spontaneously or following hormone therapy, immunotherapy or corticosteroid therapy [3-5]. This syndrome most often associates hyperuricemia hyperkalemia, hyperphosphatemia, hypocalcemia and renal failure [1]. It occurs more frequently after aggressive treatment of rapidly developing tumors such as high grade malignant lymphomas or acute leukemias [5-7]. In recent years, there have been a few case reports about TLS developing in patients with colic carcinoma.

Tumor lysis syndrome is the consequence of massive destruction of tumor cells, leading to release into the circulation of intracellular compounds. So are released the phosphates and nucleic acids, potassium and calcium. The purinosynthesis of novo results in the transformation of purine bases into uric acid and it is the main mechanism of hyperuricemia. Mitochondrial dysfunction and kidney failure acute can cause satellite acidodosis syndrome lysis. [1-3].

Kidney failure can occur mainly due to precipitation of phosphocalcic crystals or acid uric. The released calcium will bind to the phosphates, leading on the one hand to the precipitation of crystals phosphocalcic and on the other hand to paradoxal hypocalcemia. If calcium phosphate precipitates in the cardiac conducting system, serious dysrytmias can occur [6].

The low prevalence of this syndrome in the case of solid tumors is mainly explained by their low proliferative index and their relatively slow response to specific treatments [68]. Most cases of solid tumors complicated by lysis syndrome are of endocrine origin with small cells, especially of bronchial localization $[3,4,9]$. Other histological types have also been described, such as choriocarcinoma or leimyosarcoma [3]. The first lysis syndrome described in the literature for endocrine small cell colonic tumors was reported in 1988 [8].

We find similarities between our observations and those in the literature, especially massive liver metastases and a high level of LDH before chemotherapy. Such findings were considered by several authors as predisposing factors for lysis syndrome in this type of tumors. Clinical and biological anomalies associated with lysis syndrome are generally reversible when they are early diagnosed and correctly treated. However, they can be complicated by severe hyperkalemia, cardiac arrhythmias and even sudden death $[2,5,6]$. In a series of 25 cases of solid tumors complicated by tumor lysis syndrome, nine deaths have been reported [4]. Due to rarity of lysis syndrome in solid tumors, systematic preventive measures (in particular alkaline hyperhydration and administration of allopurinol) are not justified. However, due to the morbidity and mortality associated with it, it is recommended to carry out these measures as well as rigorous clinical and biological monitoring, especially in case of large mass tumors and high LDH levels, before and during all the specific treatments [7]. Quick identification of TLS is critical as treatment involves early aggressive hydration to increase renal perfusion and urine output and therefore decrease the risk of crystal precipitation and correction of electrolyte abnormalities1 [10].

\section{Conclusion}

The development of TLS in solid tumors is associated with increased mortality and therefore, a high index of suspicion is essential for early diagnosis and treatment initiation. TLS is only rarely associated with treatment of solid tumors. Precautions should be taken to avoid this potentially fatal complication.

\section{References}

1. Criscuolo M, Fianchi L, Dragonetti G, Pagano L (2016) Tumor lysis syndrome: review of pathogenesis, risk factors and management of a medical emergency. Expert Rev Hematol 9: 197-208. Link: https://bit.ly/2XGXCn 
2. Coiffier B, Altman A, Pui CH, Younes A, Cairo MS (2008) Guidelines for the management of pediatric and adult tumor lysis syndrome: an evidence-based review. J Clin Oncol 26: 2767-2778. Link: https://bit.ly/34Rv7Vx

3. Sommerhalder D, Takalkar AM, Shackelford R, Peddi P (2017) Spontaneous tumor lysis syndrome in colon cancer: a case report and literature review. Clin Case Rep 5: 2121-2126. Link: https://bit.ly/3exYyk3

4. Kearney MR, Chen EY, Stenzel P, Corless CL, Deloughery TG, et al. (2019) Colorectal Cancer-Associated Spontaneous Tumor Lysis Syndrome: a Case Report and Review of the Current Literature. J Gastrointest Cancer 50: 668 673. Link: https://bit.ly/2KbxQQh

5. Yarpuzlu AA (2003) A review of clinical and laboratory findings and treatment of tumor lysis syndrome. Clin Chim Acta 333: 13-18. Link: https://bit.ly/34lzhz2

6. Del Toro G, Morris E, Cairo MS (2005) Tumor lysis syndrome: pathophysiology definition, and alternative treatment approaches. Clin Adv Hematol Oncol 3: 54-61. Link: https://bit.ly/2wOeoG9
7. Kedar A, Grow W, Neiberger RE (1995) Clinical versus laboratory tumor lysis syndrome in children with acute leukemia. Pediatr Hematol Oncol 12: 129-134. Link: https://bit.ly/2KcsS5x

8. Heching N, Bonomi P (1988) Tumor lysis syndrome in metastatic small cell cancer. Proc Am Assoc Cancer Res 29: 179.

9. Caravaca-Fontán F, Martínez-Sáez O, Pampa-Saico S, Olmedo ME, Gomis A, et al. (2017) Tumor lysis syndrome in solid tumors: Clinical characteristics and prognosis. Med Clin (Barc) 148: 121-124. Link: https://bit.ly/3ey21yQ

10. Kearney MR, Chen EY, Stenzel P, Corless CL, Deloughery TG, et al. (2019) Colorectal Cancer-Associated Spontaneous Tumor Lysis Syndrome: a Case Report and Review of the Current Literature. J Gastrointest Cancer 50: 668 673. Link: https://bit.ly/2RL03Bm

\section{Discover a bigger Impact and Visibility of your article publication with}

\section{Peertechz Publications}

\section{Highlights}

* Signatory publisher of ORCID

* Signatory Publisher of DORA (San Francisco Declaration on Research Assessment)

* Articles archived in worlds' renowned service providers such as Portico, CNKI, AGRIS TDNet, Base (Bielefeld University Library), CrossRef, Scilit, J-Gate etc.

* Journals indexed in ICMJE, SHERPA/ROMEO, Google Scholar etc

* OAI-PMH (Open Archives Initiative Protocol for Metadata Harvesting)

* Dedicated Editorial Board for every journal

* Accurate and rapid peer-review process

* Increased citations of published articles through promotions

* Reduced timeline for article publication

Submit your articles and experience a new surge in publication services (https://www.peertechz.com/submission).

Peertechz journals wishes everlasting success in your every endeavours.

Copyright: (c) 2020 Abaza $\mathrm{H}$, et al. This is an open-access article distributed under the terms of the Creative Commons Attribution License, which permits unrestricted use, distribution, and r eproduction in any medium, provided the original author and source are credited. 